\title{
Incidence of Gastric Cancer in Patients with Laryngeal Cancer
}

\author{
Ji-Hyun Seo ${ }^{1,2}$, Hyun-Jin Kim³ , Jung Je Park ${ }^{2,4}$, Ok-Jae Lee ${ }^{3}$, Jin Pyeong Kim ${ }^{2,4}$, Seong-Ki Ahn ${ }^{2,4}$, Jeong Seok Hwa ${ }^{5}$, Jong Sil Lee ${ }^{6}$, \\ Hee-Shang Youn ${ }^{1,2}$ \\ Department of Pediatrics ${ }^{1}$, Gyeongsang Institute of Sciences ${ }^{2}$, Division of Gastroenterology, Department of Internal Medicine ${ }^{3}$, Department of \\ Otorhinolaryngology ${ }^{4}$, Department of Urology ${ }^{5}$, Department of Pathology ${ }^{6}$, Gyeongsang National University School of Medicine, Jinju, Korea
}

\begin{abstract}
Background/Aims: Gastric cancer (GC) is the second most common cancer in Korea and the most common in men in the south of the country. We investigated the incidence of synchronous GC in patients with head and neck squamous cell carcinoma (HNSCC) in the southern part of Korea.

Materials and Methods: We retrospectively reviewed the medical records of HNSCC patients treated between 2011 and 2014 . In patients with synchronous GC, evaluation included a history of smoking and alcohol consumption, endoscopic findings, Campylobacter-like organism (CLO) test, and immunohistochemical analysis of preserved HNSCC tissues.

Results: Analysis of the records of 153 HNSCC patients revealed tumors of the larynx in 56 patients (36.6\%), of the pharynx in 74 patients $(48.4 \%)$, and tumors at other locations in 23 patients (15.0\%). The mean age of patients was 66.0 years, and the men:women ratio was 8:1. Synchronous cancers were detected in 12 patients. We observed esophageal squamous cell carcinoma (SCC) in five patients (3.3\%), and gastric adenocarcinoma in seven patients (4.6\%). Synchronous GC was detected in patients with laryngeal SCC. All cases of GC were classified as early GC.

Conclusions: Synchronous GC was as frequent as esophageal SCC in patients with HNSCC, and all cases of GC were observed to be early stage cancers in this study. Thorough endoscopic examination should be performed in patients with laryngeal cancer to detect the presence of synchronous GC. (Korean J Helicobacter Up Gastrointest Res 2017;17:190-194)
\end{abstract}

Key Words: Gastric cancer; Laryngeal cancer; Second primary neoplasm

\section{INTRODUCTION}

Double primary cancers or synchronous cancers are defined as cancers that occur simultaneously in unrelated organs in one person. ${ }^{1}$ The pathogenesis of synchronous cancers is based on the concept of field cancerization, in which repeated exposure to common carcinogens leads to an accumulation of genetic alterations, resulting in the development of independent cancers. ${ }^{2}$ In patients with head and neck squamous cell carcinoma (HNSCC), esophageal cancer is the most common synchronous cancer. ${ }^{3-6}$ In Korea, esophageal cancer is detected in $5.0 \sim 7.1 \%$ of patients with $\mathrm{HNSCC}^{4,7}$ and occurs most frequently in HNSCC patients with tumors of the hypopharynx. ${ }^{7,8}$

Received: July 6, 2017 Revised: September 15, 2017 Accepted: September 18, 2017

Corresponding author: Jung Je Park

Department of Otorhinolaryngology, Gyeongsang National University Hospital, Gyeongsang National University School of Medicine, 79 Gangnam-ro, Jinju 52727, Korea

Tel: +82-55-750-8698, Fax: +82-55-752-9339, E-mail: capetown@hanmail.net The clinical data and the biospecimens used in this study were provided by the Gyeongsang National University Hospital, which is a member of the Korea Biobank Network Nation Biobank of Korea, which is supported by the Ministry of Health, Welfare and Family Affairs.

This work was supported by the fund of research promotion program, Gyeongsang National University, 2014 (RPP-2014-025).
Related risk factors for esophageal cancer include a positive history of smoking. ${ }^{7}$ Histologically, most head and neck cancers and esophageal cancers are squamous cell carcinoma. Tumors with the same histology, localization to an adjacent anatomic area of the upper airway and esophagus, and exposure to synchronous smoking may be associated with the development of synchronous cancers in the upper airway and esophagus. ${ }^{2}$

In East-Asia, including Korea and Japan, the prevalence of gastric cancer (GC) is high. ${ }^{910}$ In a study conducted in Japan, synchronous esophageal cancer and GC were detected in 23 patients $(8.0 \%)$ and 8 patients $(2.8 \%)$ of 287 patients with HNSCC during initial endoscopic examination. ${ }^{8}$ Histologically, most GCs are adenocarcinoma, and the risk factors for GC are Helicobacter pylori infection and certain life habits, such as salty diet, smoking, and alcohol consumption. ${ }^{11} \mathrm{GC}$ is the second most common cancer in Korea followed by thyroid carcinoma; ${ }^{10}$ however, the incidence of synchronous GC in patients with HNSCC has not been reported to date. In the present study, we investigated the incidence of synchronous GC

Copyright $\odot 2017$ Korean College of Helicobacter and Upper Gastrointestinal Research

(a) The Korean Journal of Helicobacter and Upper Gastrointestinal Research is an Open-Access Journal. All articles are distributed under the terms of the Creative Commons Attribution Non-Commercia License (http://creativecommons.org/licenses/by-nc/4.0) which permits unrestricted non-commercial use, distribution, and reproduction in any medium, provided the original work is properly cited. 
in patients with HNSCC in the Western Gyeongnam area of Korea.

\section{MATERIALS AND METHODS}

\section{Patients}

The Institutional Review Board (IRB) of the Gyeongsang National University Hospital (GNUH) approved this retrospective study and waived the need for informed consent (GNUH-IRB no. 2015-07-017). A total of 153 patients was identified in an IRB-approved retrospective search of the electronic medical records of patients diagnosed with head and neck cancer who underwent upper gastrointestinal endoscopy at the Cancer Center (Department of Otolaryngology) of GNUH between January 2011 and December 2014.

\section{Study design and setting}

All patients underwent a primary staging workup for laryngeal cancer that included blood tests, oral cavity inspection, endoscopic examination of the pharynx and larynx, computed tomography (CT) of the head and neck, chest, and abdomen, whole body ${ }^{18} \mathrm{~F}-\mathrm{FDG}$ positron emission tomography (PET)-CT, and upper esophagogastroduodenoscopy.

Primary HNSCC was classified as follows: larynx, phar- ynx, or oral cavity. Staging of the laryngeal carcinoma was performed according to the tumor-node-metastasis (TNM) staging system. ${ }^{12}$

Synchronous GC was defined as gastric adenocarcinoma detected during the initial diagnosis of primary HNSCC. The final diagnosis was made on the basis of pathologic examinations.

In cases with secondary early gastric cancer (EGC), the evaluation included a history of smoking and alcohol consumption, Campylobacter-like organism test (CLO test), endoscopic examination, and immunohistochemical studies of human papilloma virus (HPV), P16, P53, and epidermal growth factor receptor (EGFR) using paraffin block-embedded tissues to examine the association with HPV (P16) or other cancer risk factors (EGFR and P53).

\section{RESULTS}

In the 153 patients with $\mathrm{HNSCC}$, tumors were detected in the larynx in 56 patients (36.6\%), pharynx in 74 patients (48.4\%), and other locations in 23 patients (15.0\%) (Fig. 1). The larynx was the second most common site of primary HNSCC. The median age of the patients was 66.0 years (range, $27 \sim 87$ years) and the male to female ratio was 8:1 (136:17). The baseline characteristics of the patients are shown in Table 1.

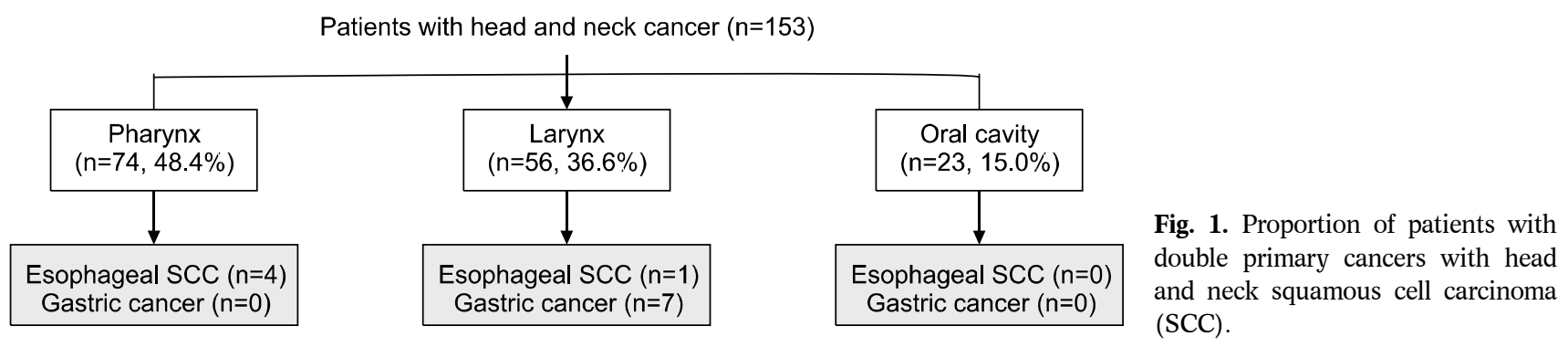

Table 1. Demographic Data of the 153 Patients with Head and Neck Squamous Cell Carcinoma Included in the Study

\begin{tabular}{cccccc}
\hline Location of HNSCC & Subject & Median age $(\mathrm{yr})$ & Sex (female:male) & Esophageal SCC & Gastric adenocarcinomas \\
\hline Larynx & $56(36.6)$ & $69.5(38 \sim 87)$ & $3: 53$ & $1(1.8)$ & $7(12.5)$ \\
Pharynx & $74(48.4)$ & $62.5(27 \sim 86)$ & $13: 61$ & $4(5.4)$ & $0(0)$ \\
Oral cavity & $23(15.0)$ & $66.0(47 \sim 83)$ & $1: 22$ & $0(0)$ & $0(0)$ \\
Total & $153(100)$ & $66.0(27 \sim 87)$ & $17: 136$ & $5(3.3)$ & $7(4.6)$ \\
\hline
\end{tabular}

Values are presented as number (\%), median (range), or number only.

HNSCC, head and neck squamous cell carcinoma; SCC, squamous cell carcinoma. 
Table 2. Clinical and Laboratory Findings of Patients with Laryngeal Cancer and Early Gastric Cancer

\begin{tabular}{|c|c|c|c|c|c|c|c|c|c|c|c|c|c|c|}
\hline \multirow{2}{*}{$\begin{array}{c}\text { Patient } \\
\text { no. }\end{array}$} & \multirow{2}{*}{$\begin{array}{l}\text { Age } \\
\text { (yr) }\end{array}$} & \multirow{2}{*}{ Sex } & \multirow{2}{*}{ Location } & \multirow{2}{*}{$\begin{array}{l}\text { History of } \\
\text { smoking }\end{array}$} & \multirow{2}{*}{$\begin{array}{c}\text { History of } \\
\text { alcohol }\end{array}$} & \multicolumn{3}{|c|}{ Stage of laryngeal cancer } & \multicolumn{4}{|c|}{ Immunohistochemistry finding $^{a}$} & \multirow{2}{*}{$\begin{array}{l}\text { Gastric } \\
\text { cancer }\end{array}$} & \multirow{2}{*}{$\begin{array}{l}\text { CLO } \\
\text { test }\end{array}$} \\
\hline & & & & & & Tumor & Node & Metastasis & EGFR & HPV & P16 & P53 & & \\
\hline 1 & 72 & Female & Epiglottis & 1 & 0 & 2 & 1 & 0 & +++ & - & - & - & EGC IIc & - \\
\hline 2 & 76 & Male & Glottis & 0 & 0 & 1 & 0 & 0 & +++ & NA & - & - & EGC IIc & - \\
\hline 3 & 38 & Male & Glottis & 1 & 1 & 1 & 0 & 0 & +++ & - & - & - & EGC & + \\
\hline 4 & 62 & Male & Glottis & 0 & 0 & 1 & 0 & 0 & +++ & NA & - & + & EGC & + \\
\hline 5 & 73 & Male & Supraglottis & 1 & 1 & 2 & 0 & 0 & + & - & +++ & + & EGC IIb & - \\
\hline 6 & 68 & Male & Supraglottis & 0 & 0 & 2 & 2 & 0 & + & - & - & - & EGC IIc & NA \\
\hline 7 & 75 & Male & Supraglottis & 1 & 1 & 2 & 0 & 0 & +++ & - & - & - & EGC & - \\
\hline
\end{tabular}

EGFR, epidermal growth factor receptor; HPV, human papilloma virus; CLO, Campylobacter-like organism; EGC, early gastric cancer; NA, not available.

${ }^{a}$ Immunohistochemical analyses showed that five patients had high a EGFR expression $(+++)$, one was P16 positive, and two were P53 positive. In one patient with positive P16, the degree of EGFR was low (+).

A second primary cancer was detected in 12 patients (7.8\%). Five patients $(3.3 \%)$ had esophageal squamous cell carcinoma (SCC) and seven patients (4.6\%) had gastric adenocarcinoma. All gastric adenocarcinomas occurred in patients with laryngeal SCC, and four cases of esophageal SCC occurred in patients with pharyngeal SCC (Table 1). One patient had esophageal SCC and EGC. All second primary gastrointestinal cancers were detected by upper esophagogastroduodenoscopy and were not detected by PET-CT.

Table 2 lists the clinical characteristics of patients with synchronous GC. There was only one woman. All patients were diagnosed with EGC. The treatment method for EGC was endoscopic mucosal resection (EMR), except one case that was managed with gastrectomy because of recurrence of EGC. The low numbers of patients had a positive history of smoking ( $\mathrm{n}=4)$ and alcohol consumption $(n=3)$. The stage of the primary HNSCC was T1 or $\mathrm{T} 2$ and $\mathrm{N} 0$ or $\mathrm{N} 1$ without metastasis.

Half of the patients had a positive CLO test. Recurrence of EGC was detected in only one patient who underwent gastrectomy. There was no evidence of poor prognosis of EGC. Immunohistochemical analyses showed that five patients had high a EGFR expression (+++), one was $\mathrm{P} 16$ positive, and two were $\mathrm{P} 53$ positive. In one patient with positive P16, the degree of EGFR was low (+).

\section{DISCUSSION}

In this study, we investigated the incidence of synchro- nous GC in patients with HNSCC due to GC is the highest prevalence in the Western Gyeongnam area. Among 153 patients with HNSCC, the overall incidence of synchronous GC was $4.6 \%$ and the incidence of synchronous esophageal SCC was 3.3\%. These results differed from those of a previous study in Japan, in which the incidence of synchronous esophageal SCC (8.0\%) was higher than that of synchronous GC (2.8\%) among $287 \mathrm{pa}^{-}$ tients with HNSCC, ${ }^{8}$ and from other reports in Korea showing that esophageal cancer is more prevalent than GC in patients with HNSCC., The high rate of synchronous GC in patients with HNSCC in the present study could be related to the fact that GC is the most common cancer among men in the southern part of Korea. ${ }^{13}$

Synchronous cancers occurring in the aerodigestive tract are associated with etiologic factors, such as smoking and alcohol consumption. ${ }^{14}$ Smoking is an important risk factor for synchronous esophageal SCC in patients with HNSCC. ${ }^{7}$ Smoking and alcohol are also risk factors for GC. ${ }^{11}$ However, in the present study, no correlation between a positive history of smoking or alcohol consumption and the incidence of synchronous GC in patients with HNSCC was shown and it might be attributed to the too low number of patients with synchronous GC.

A previous study showed that synchronous esophageal SCC was detected in patients with HNSCC located in the pharynx and hypopharynx. ${ }^{7}$ A study for comparison of the incidence and patterns of second primary malignancies between patients with SCC of the larynx and hypopharynx showed that the incidence of a second pri- 
mary malignancy is higher in patients with hypopharyngeal SCC than in those with laryngeal SCC, and second primary malignancies occur more frequently in the respiratory axis (lung and larynx) in laryngeal SCC and in the digestive axis (oral cavity, pharynx, and esophagus) in hypopharyngeal SCC. ${ }^{15}$ However, in the present study, second primary malignancies were more frequent in patients with laryngeal SCC than in those with hypopharyngeal SCC, and the GC was commonly observed in patients with laryngeal SCC. The exact reason cannot be elucidated in this study. However, high prevalence of GC in Western Gyeongnam province might be the reason.

H. pylori infection is one of the risk factors for $\mathrm{GC}^{16}$ and is also associated with HNSCC. ${ }^{16}$ However, in the present study, $H$. pylori infection was detected in $<50 \%$ of patients with HNSCC and GC using the CLO test, which might be related to the low numbers of patient. In Korea, the most common second primary cancer in patients with GC is colonic adenocarcinoma, ${ }^{17}$ which confirms the cancer field theory. ${ }^{2}$ HNSCC is the seventh most common double primary cancer in patients with GC. ${ }^{17}$ The upper endoscopic examination is usually performed in Korea as part of the staging workup in patients with HNSCC. Our results suggested that thorough endoscopic examination should be performed in patients with laryngeal cancer to detect the presence of synchronous GCs and a careful laryngeal and pharyngeal examination needs to be performed in patients with GC who have a positive history of smoking during upper gastroendoscopy.

Synchronous or metachronous cancer is an important factor associated with the poor prognosis of patients with head and neck cancers, even when the cancer is adequately controlled. ${ }^{7,18,19}$ The prognosis of synchronous or metachronous esophageal SCC is important for the prognosis of patients with HNSCC. ${ }^{7,18,19}$ However, in the present study, all synchronous GCs were early stage tumors and all of them were initially managed with EMR. Our results showed that GC detected in the early stages does not affect the prognosis of patients with HNSCC, highlighting the importance of a thorough upper esophagogastroduodenoscopic examination to detect EGC instead of PET-CT and abdominal CT.

The present study has several limitations, including its nature as a single center study, the lack of a comparison between the presence and absence of GC, and the short duration of the study.

The results of the present study showed that GC is the most common synchronous cancer in patients with laryngeal SCC, which could be related to the high prevalence of GC among men in the southern region of Korea. ${ }^{13}$ Synchronous GC detected in the early stages can be treated by EMR. Esophageal SCC was the second most common synchronous cancer in patients with HNSCC. Therefore, regardless of the smoking and/or alcohol consumption history, patients with laryngeal SCC should undergo intensive endoscopic screening to detect synchronous esophageal cancer and GC because of its high prevalence in that area.

\section{REFERENCES}

1. Sung MS, Han SY, Choi SR, Shin WW. Four cases of double primary cancer. Korean J Gastrointest Endosc 1993;13:69-74.

2. Slaughter DP, Southwick HW, Smejkal W. Field cancerization in oral stratified squamous epithelium; clinical implications of multicentric origin. Cancer 1953;6:963-968.

3. Chuang SC, Scelo G, Tonita JM, et al. Risk of second primary cancer among patients with head and neck cancers: a pooled analysis of 13 cancer registries. Int J Cancer 2008;123: 2390-2396.

4. Lim H, Kim DH, Jung HY, et al. Clinical significance of early detection of esophageal cancer in patients with head and neck cancer. Gut Liver 2015;9:159-165.

5. Scherübl H, von Lampe B, Faiss S, et al. Screening for oesophageal neoplasia in patients with head and neck cancer. Br J Cancer 2002;86:239-243.

6. Petit T, Georges C, Jung GM, et al. Systematic esophageal endoscopy screening in patients previously treated for head and neck squamous-cell carcinoma. Ann Oncol 2001;12:643-646.

7. Kim DH, Gong EJ, Jung HY, et al. Clinical significance of intensive endoscopic screening for synchronous esophageal neoplasm in patients with head and neck squamous cell carcinoma. Scand J Gastroenterol 2014;49:1486-1492.

8. Tei K, Shinomiya T, Shimada T, et al. Value of upper gastrointestinal endoscopic examination of head and neck cancer patients. Nihon Jibiinkoka Gakkai Kaiho 2000;103:754-760.

9. Leung WK, Wu MS, Kakugawa Y, et al. Screening for gastric cancer in Asia: current evidence and practice. Lancet Oncol 2008;9:279-287.

10. Jung KW, Won YJ, Kong HJ, et al. Cancer statistics in Korea: incidence, mortality, survival, and prevalence in 2012. Cancer Res Treat 2015;47:127-141. 
11. den Hoed CM, Kuipers EJ. Gastric cancer: how can we reduce the incidence of this disease? Curr Gastroenterol Rep 2016; 18:34.

12. Washington K. 7th edition of the AJCC cancer staging manual: stomach. Ann Surg Oncol 2010;17:3077-3079.

13. National Cancer Information Center. Annual report of cancer statics in Korea in 2013 [Internet]. Korea Central Cancer Registry Cancer Registration \& Statistics Branch, Division of Cancer Registration \& Surveillance, National Cancer Center, Korea, 2015 [cited 2015 Dec]. Available from: https://goo.gl/DPQw9H.

14. Schistosomes, liver flukes and Helicobacter pylori. IARC Working Group on the Evaluation of Carcinogenic Risks to Humans. Lyon, 7-14 June 1994. IARC Monogr Eval Carcinog Risks Hum 1994;61:1-241.

15. Chu PY, Chang SY, Huang JL, Tai SK. Different patterns of second primary malignancy in patients with squamous cell carcinoma of larynx and hypopharynx. Am J Otolaryngol 2010;31:
168-174.

16. Lukeš P, Pavlík E, Potuznikova B, et al. Detection of Helicobacter pylori in oropharyngeal lymphatic tissue with real-time PCR and assessment of its carcinogenic potential. Eur Arch Otorhinolaryngol 2014;271:399-405.

17. Kim JY, Jang WY, Heo MH, et al. Metachronous double primary cancer after diagnosis of gastric cancer. Cancer Res Treat 2012; 44:173-178.

18. Erkal HS, Mendenhall WM, Amdur RJ, Villaret DB, Stringer SP. Synchronous and metachronous squamous cell carcinomas of the head and neck mucosal sites. J Clin Oncol 2001;19: 1358-1362.

19. Lippman SM, Hong WK. Second malignant tumors in head and neck squamous cell carcinoma: the overshadowing threat for patients with early-stage disease. Int J Radiat Oncol Biol Phys 1989;17:691-694. 